\title{
Microarray data analysis reveals differentially expressed genes in prolactinoma
}

\author{
W. ZHOU*, C. MA, Z. YAN \\ Department of Neurosurgery, Henan Provincial People's Hospital, Zhengzhou 450003, China \\ ${ }^{*}$ Correspondence: weiizhouu@gmail.com
}

Received February 24, 2014 / Accepted June 4, 2014

\begin{abstract}
Gene expression profiles of prolactinomas were compared with those of normal pituitary glands to identify differentially expressed genes (DEGs). Protein-protein interaction (PPI) analysis and protein complex prediction were performed to reveal the cross-talk between these genes and molecular mechanisms underlying the disease. Microarray data were downloaded from Gene Expression Omnibus. DEGs were screened using GEO2R and false discovery rate (FDR) $<0.05$ was set as the cut-off. Protein-protein interaction (PPI) network was constructed with information from STRING and significant KEGG pathways were unveiled. Protein complexes were predicted using ClusterONE from Cytoscape and then validated in terms of pathways, protein domain, cellular localization and literatures. A total of 1712 genes (1911 probes) were found to be differentially expressed in prolactinoma. Interactions were identified among 121 protein products. Nineteen significant pathways $(\mathrm{FDR}<0.05)$ were acquired and pathways in cancer was the top one. Pathways linked to myeloid leukemia and tryptophan metabolism were also enriched in the DEGs. Four protein complexes were predicted and then validated. They were associated with focal adhesion, cytoskeleton, metabolism of tryptophan, arginine and proline as well as aldehyde dehydrogenases. They might play important roles in the pathogenesis of prolactinoma. In present study, not only DEGs were provided, but also PPIs and protein complexes were discussed. These findings promoted the knowledge about prolactinoma and provided novel candidate targets for the therapy development of prolactinoma.
\end{abstract}

Key words: prolactinoma, differentially expressed genes, protein-protein interaction network, protein complex

Prolactinoma is the most common type of pituitary tumor as it accounts for $60 \%$ of functional pituitary adenomas $[1,2]$. It causes hyperprolactinemia and exerts pressure on surrounding tissues. Dopamine agonist can be used to inhibit prolactin secretion. Surgery is another option while medical therapy fails to reduce prolactin levels and tumor size. However, approximately $20 \%$ of prolactinomas may exhibit either dopamine agonist resistance or high recurrence rates after operation [3]. Therefore, a better understandin the pathogenesis of prolactinoma is necessary for development of improved therapies.

Many studies demonstrate that growth factors play an important role in the pathogenesis of prolactinoma. Santos-Silva et al. indicate that human epidermal growth factor receptor 2 (HER2) /ErbB2 receptor signaling plays a role in prolactinoma cell proliferation and thus can be targeted to treat this disease [4]. Estrogen can induce expression of many growth factors via estrogen receptor $\alpha$. Lv et al. report that estrogen receptor a correlates with prolactin (PRL) levels and tumor volume, and may be an effective therapy target [5]. Cooper et al. further demonstrate that prolactinoma expression of specific ErbB receptors is associated with tumor invasion, symptoms, and response to dopamine agonists [6].

Several transcription factors (TFs) are also revealed in prolactinoma. Tong et al. identify CCAAT-enhancer-binding protein $\delta$ (CEBPD) transcription factor as a critical gene that partially suppresses both PRL expression and lactotroph cell proliferation [7]. Palmieri et al. find that pituitary-specific transcription factor 1 (PIT1) upregulation by HMGA proteins has a role in pituitary tumorigenesis [8]. Expression of steroidogenic factor 1 and PIT1 can be used for classification of rat pituitary adenomas [9].

Furthermore, Jiang et al. have already applied fiber-optic BeadArray approach combined with Kyoto Encyclopedia of Genes and Genomes (KEGG) pathway analysis of differential gene expression in prolactinoma. This study has found that 27 up- regulated genes and 182 down- regulated genes were 
identified using array analysis. KEGG pathway analysis showed that P53 and GnRH signaling pathways might be involved in tumorigenesis of prolactinomas. Compared with the above study, we attached more importance to protein interactions and prediction of protein complexes involved in significant pathways, in addition to analysis of DEGs and pathways in prolactinomas. Specifically, in present study, microarray-based gene expression profiling was performed to identify differentially expressed genes (DEGs) between prolactinomas and normal pituitary glands. Protein-protein interactions (PPIs) and protein complexes were explored with bioinformatic tools to gain insights into the pathogenesis of prolactinoma.

\section{Materials and methods}

Microarray data. Microarray data set GSE36314 [10] was downloaded from Gene Expression Omnibus. It included 4 human prolactinoma samples and 3 normal pituitary gland samples. GPL8300 [HG_U95Av2] Affymetrix Human Genome U95 Version 2 Array was utilized to obtained gene expression profiles.

Screening of DEGs. DEGs were screened using GEO2R. GEO2R employed GEOquery of BioConductor and package limma of $R$ to finish the statistical analysis [11]. Package limma (Linear Models for Microarray Analysis) was used to perform multiple-testing corrections on p-value and thus minimized false discovery rate (FDR) [12]. FDR $<0.05$ was set as the cutoff. KEGG pathways enrichment analysis was performed for

Table 1. Top 10 up- and down-regulated DEGs between control and prolactinomas

\begin{tabular}{lcccc}
\hline & Gene & $\log F \mathrm{p}$ & p-value & FDR \\
\hline UP-DEG & GH1 & 6.82 & $4.05 \mathrm{E}-12$ & $5.11 \mathrm{E}-08$ \\
& CGA & 6.5 & $9.96 \mathrm{E}-09$ & $1.80 \mathrm{E}-05$ \\
& POMC & 6.14 & $2.29 \mathrm{E}-10$ & $1.45 \mathrm{E}-06$ \\
& GAL & 5.87 & $1.49 \mathrm{E}-09$ & $4.70 \mathrm{E}-06$ \\
& TSHB & 4.99 & $1.65 \mathrm{E}-03$ & $9.55 \mathrm{E}-02$ \\
& GH2 & 4.75 & $8.01 \mathrm{E}-09$ & $1.69 \mathrm{E}-05$ \\
& CSHL1 & 4.64 & $1.97 \mathrm{E}-08$ & $2.51 \mathrm{E}-05$ \\
& RBP4 & 4.49 & $1.26 \mathrm{E}-06$ & $9.35 \mathrm{E}-04$ \\
& DLK1 & 4.26 & $2.45 \mathrm{E}-05$ & $8.55 \mathrm{E}-03$ \\
& LHB & 4.23 & $5.57 \mathrm{E}-10$ & $2.34 \mathrm{E}-06$ \\
IGSF1 & -1.46 & $1.20 \mathrm{E}-03$ & $8.41 \mathrm{E}-02$ \\
& VWF & -1.48 & $1.21 \mathrm{E}-03$ & $8.41 \mathrm{E}-02$ \\
B2M & -1.51 & $2.98 \mathrm{E}-04$ & $4.13 \mathrm{E}-02$ \\
& RGS5 & -1.52 & $2.53 \mathrm{E}-02$ & $2.62 \mathrm{E}-01$ \\
& HLA-CHLA-B & -1.56 & $2.41 \mathrm{E}-06$ & $1.52 \mathrm{E}-03$ \\
& FN1 & -1.66 & $7.10 \mathrm{E}-03$ & $1.69 \mathrm{E}-01$ \\
& THSD7A & -1.68 & $5.23 \mathrm{E}-04$ & $5.85 \mathrm{E}-02$ \\
CDR1 & -1.7 & $3.49 \mathrm{E}-02$ & $2.93 \mathrm{E}-01$ \\
& TMEM158 & -1.75 & $1.00 \mathrm{E}-03$ & $8.13 \mathrm{E}-02$ \\
ITGA7 & -1.91 & $2.04 \mathrm{E}-04$ & $3.57 \mathrm{E}-02$ \\
\hline
\end{tabular}

DEG: differentially expressed genes; FDR: false discovery rate; log FC; log fold change up- and down-regulated DEGs using database for annotation, visualization, and integrated discovery (DAVID) [13]. A pvalue $<0.05$ was used as a strict threshold for the pathway enrichment analysis.

Construction of PPI network. PPI network was constructed with information from STRING [14], which collects interaction information from genomic context, high-throughput experiments, coexpression and previous knowledge. Interactions with confidence $>0.4$ were retained and then visualized using Cytoscape. KEGG significant pathways were marked and they might play roles in the development of prolactinoma. FDR $<0.05$ was set as the criterion.

Prediction of protein complex. Protein complexes were predicted using ClusterONE (Clustering with Overlapping Neighborhood Expansion) from Cytoscape. ClusterONE adopted graph clustering to handle weighted graphs and thus revealed overlapping clusters [15]. The minimum size was set as 3 , which meant that cluster with less than 3 genes would be ignored, and minimum density was set as "auto". The score given by STRING was considered as the weight (i.e. edge weight).

Validation of predicted protein complexes. Four methods could be used to validate the predicted protein complexes: KEGG pathway enrichment analysis; protein domain; cellular components enrichment analysis; Gene ontology (GO) term enrichment analysis. DAVID was used to carry out these analysis.

\section{Results}

DEGs. A total of 1911 probes (corresponding to 1712 genes) were found to be differentially expressed according to the threshold (FDR< 0.05). Among these DEGs, top 10 upand down-regulated genes were listed in Table 1. As shown in Table 2, up-regulated DEGs were significantly enriched in 7 pathways. Of the 7 pathways, Huntington's disease, Parkinson's disease and oxidative phosphorylation pathways were most significant. Down-regulated DEGs were significantly enriched in 21 pathways. Of the 21 pathways, most significantly enriched pathways included colorectal cancer, pathways in cancer, neurotrophin signaling pathway, MAPK signaling pathway and cell adhesion molecules (CAMs) pathways.

PPI network of DEGs. A total of 1081 proteins were found in STRING (Figure 1). Interactions were identified among 121 proteins.

Enriched KEGG pathways in PPI network. A total of 19 KEGG pathways were obtained according to the threshold $(\mathrm{FDR}<0.05)$ (Table 3$)$. The top term was "pathways in cancer" with 50 genes. Two pathways related to myeloid leukemia were also enriched. There's certain association between myeloid leukemia and pituitary prolactinoma according to a recent medical report [16]. Tryptophan metabolites, such as serotonin (5-HT) and kynerenines (KYNs), are strong and effective substances regulating mood and behavior. Hormone secreted by the pituitary gland can regulate the metabolism of tryptophan 
[17]. Meanwhile, tryptophan metabolic process can in turn regulate neurogenesis in the hypothalamic - pituitary - adrenal axis [18]. Therefore, it's not unexpected that this pathway was enriched in the DEGs.

Protein complexes in DEGs. A total of 4 protein complexes were revealed using ClusterONE from Cytoscape. Their PPI networks are shown in Figure 2. Genes included in the enriched KEGG pathways were in red. Genes in complex
1 were involved in a range of important pathways, such as focal adhesion (hsa04510), ECM-receptor interaction (hsa04512), arrhythmogenic right ventricular cardiomyopathy (hsa05412), small cell lung cancer (hsa05222) and regulation of actin cytoskeleton (hsa04810) (Table 4). Complex 1 was mainly enriched outside the cell membrane. Complex 3 was implicated in tryptophan (hsa00380), arginine and proline metabolisms (hsa00330), as well as decomposition of limonene and pinene

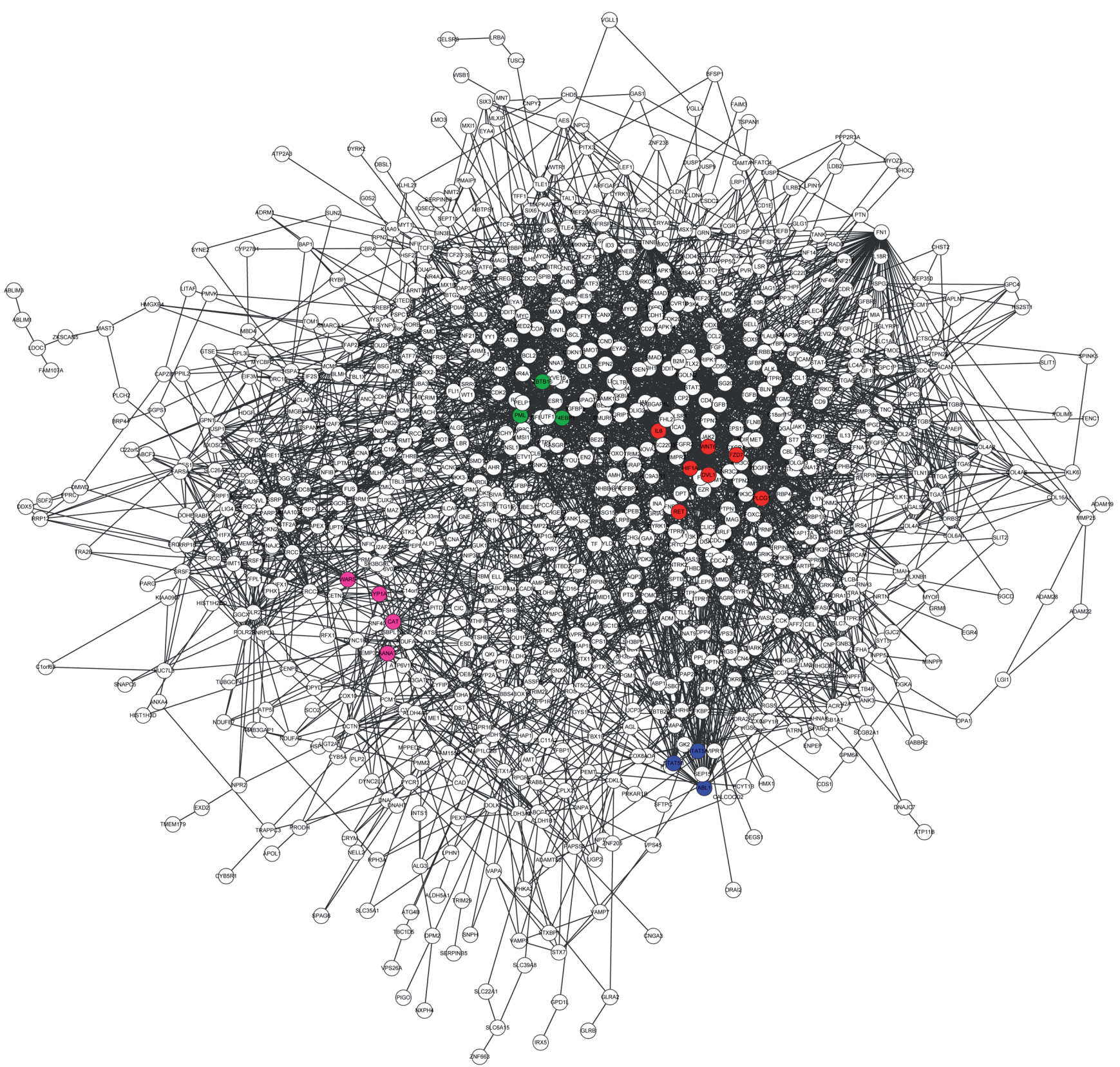

Figure 1. The PPI network for DEGs. Genes included in the top 4 KEGG pathways were shown in various colors. Red genes were included in pathways in cancer; green genes in acute myeloid leukemia pathway; blue genes in chronic myeloid leukemia pathway; violet genes in tryptophan metabolism pathway. DEG: differentially expressed genes 
Table 2. KEGG pathway enrichment analysis of DEGs in prolactinomas

\begin{tabular}{|c|c|c|c|c|}
\hline Category & KEGG ID & Term & Number of genes & p-value \\
\hline \multirow[t]{7}{*}{ UP-DEG } & hsa05016 & Huntington's disease & 32 & $4.55 \mathrm{E}-07$ \\
\hline & hsa05012: & Parkinson's disease & 24 & 7.09E-06 \\
\hline & hsa00190: & Oxidative phosphorylation & 24 & $9.28 \mathrm{E}-06$ \\
\hline & hsa03010 & Ribosome & 19 & $9.66 \mathrm{E}-06$ \\
\hline & hsa05010 & Alzheimer's disease & 25 & $1.34 \mathrm{E}-04$ \\
\hline & hsa00620: & Pyruvate metabolism & 8 & $1.41 \mathrm{E}-02$ \\
\hline & hsa00650: & Butanoate metabolism & 7 & $2.16 \mathrm{E}-02$ \\
\hline \multirow[t]{14}{*}{ DOWN-DEG } & hsa05210: & Colorectal cancer & 17 & $1.38 \mathrm{E}-04$ \\
\hline & hsa05200: & Pathways in cancer & 41 & $1.75 \mathrm{E}-04$ \\
\hline & hsa04722: & Neurotrophin signaling pathway & 20 & $6.47 \mathrm{E}-04$ \\
\hline & hsa04010: & MAPK signaling pathway & 33 & $1.08 \mathrm{E}-03$ \\
\hline & hsa04514: & Cell adhesion molecules (CAMs) & 20 & $1.41 \mathrm{E}-03$ \\
\hline & hsa05220: & Chronic myeloid leukemia & 14 & $1.46 \mathrm{E}-03$ \\
\hline & hsa05212: & Pancreatic cancer & 13 & $3.11 \mathrm{E}-03$ \\
\hline & hsa05214: & Glioma & 11 & $9.51 \mathrm{E}-03$ \\
\hline & hsa05221: & Acute myeloid leukemia & 10 & $1.57 \mathrm{E}-02$ \\
\hline & hsa00380: & Tryptophan metabolism & 8 & $1.71 \mathrm{E}-02$ \\
\hline & hsa04510: & Focal adhesion & 23 & $1.77 \mathrm{E}-02$ \\
\hline & hsa05218: & Melanoma & 11 & $2.12 \mathrm{E}-02$ \\
\hline & hsa05213: & Endometrial cancer & 9 & $2.32 \mathrm{E}-02$ \\
\hline & hsa04144: & Endocytosis & 21 & $2.47 \mathrm{E}-02$ \\
\hline$\nabla$ & hsa04512: & ECM-receptor interaction & 12 & $2.64 \mathrm{E}-02$ \\
\hline$\nabla$ & hsa05222: & Small cell lung cancer & 12 & $2.64 \mathrm{E}-02$ \\
\hline$\otimes$ & hsa05223: & Non-small cell lung cancer & 9 & $2.86 \mathrm{E}-02$ \\
\hline$\otimes$ & hsa04012: & ErbB signaling pathway & 12 & $3.32 \mathrm{E}-02$ \\
\hline$\nabla$ & hsa04930: & Type II diabetes mellitus & 8 & $3.84 \mathrm{E}-02$ \\
\hline$\otimes$ & hsa05215 & Prostate cancer & 12 & $3.84 \mathrm{E}-02$ \\
\hline Q & hsa04270 & Vascular smooth muscle contraction & 14 & 4.03E-02 \\
\hline
\end{tabular}

DEG: differentially expressed genes; KEGG: Kyoto Encyclopedia of Genes and Genomes

Table 3. Significantly enriched pathways in the PPI network

\begin{tabular}{|c|c|c|c|c|c|}
\hline No. & KEGG ID & Term & Number of genes & p-value & FDR \\
\hline 1 & hsa05200 & Pathways in cancer & 50 & $5.00 \mathrm{E}-07$ & $1.06 \mathrm{E}-04$ \\
\hline 2 & hsa05221 & Acute myeloid leukemia & 13 & $1.64 \mathrm{E}-04$ & $1.60 \mathrm{E}-02$ \\
\hline 3 & hsa05220 & Chronic myeloid leukemia & 15 & $2.26 \mathrm{E}-04$ & $1.60 \mathrm{E}-02$ \\
\hline 4 & hsa00380 & Tryptophan metabolism & 10 & $3.15 \mathrm{E}-04$ & $1.67 \mathrm{E}-02$ \\
\hline 5 & hsa04010 & MAPK signaling pathway & 38 & $4.18 \mathrm{E}-04$ & $1.69 \mathrm{E}-02$ \\
\hline 6 & hsa05210 & Colorectal cancer & 13 & $4.78 \mathrm{E}-04$ & $1.69 \mathrm{E}-02$ \\
\hline 7 & hsa05215 & Prostate cancer & 16 & $6.91 \mathrm{E}-04$ & $1.85 \mathrm{E}-02$ \\
\hline 8 & hsa04810 & Regulation of actin cytoskeleton & 29 & $6.98 \mathrm{E}-04$ & $1.85 \mathrm{E}-02$ \\
\hline 9 & hsa05222 & Small cell lung cancer & 16 & $8.90 \mathrm{E}-04$ & $2.10 \mathrm{E}-02$ \\
\hline 10 & hsa05100 & Bacterial invasion of epithelial cells & 13 & $1.38 \mathrm{E}-03$ & $2.64 \mathrm{E}-02$ \\
\hline 11 & hsa00330 & Arginine and proline metabolism & 11 & $1.41 \mathrm{E}-03$ & $2.64 \mathrm{E}-02$ \\
\hline 12 & hsa05218 & Melanoma & 13 & $1.59 \mathrm{E}-03$ & $2.64 \mathrm{E}-02$ \\
\hline 13 & hsa00903 & Limonene and pinene degradation & 4 & $1.62 \mathrm{E}-03$ & $2.64 \mathrm{E}-02$ \\
\hline 14 & hsa05412 & Arrhythmogenic right ventricular cardiomyopathy (ARVC) & 13 & $2.35 \mathrm{E}-03$ & $3.56 \mathrm{E}-02$ \\
\hline 15 & hsa04510 & Focal adhesion & 27 & $2.67 \mathrm{E}-03$ & 3.77E-02 \\
\hline 16 & hsa04512 & ECM-receptor interaction & 15 & $3.10 \mathrm{E}-03$ & $4.10 \mathrm{E}-02$ \\
\hline 17 & hsa05212 & Pancreatic cancer & 12 & $3.70 \mathrm{E}-03$ & $4.62 \mathrm{E}-02$ \\
\hline 18 & hsa05213 & Endometrial cancer & 10 & $4.14 \mathrm{E}-03$ & 4.73E-02 \\
\hline 19 & hsa00410 & beta-Alanine metabolism & 6 & $4.23 \mathrm{E}-03$ & $4.73 \mathrm{E}-02$ \\
\hline
\end{tabular}

KEGG: Kyoto Encyclopedia of Genes and Genomes; PPI: protein-protein interaction; FDR: false discovery rate 

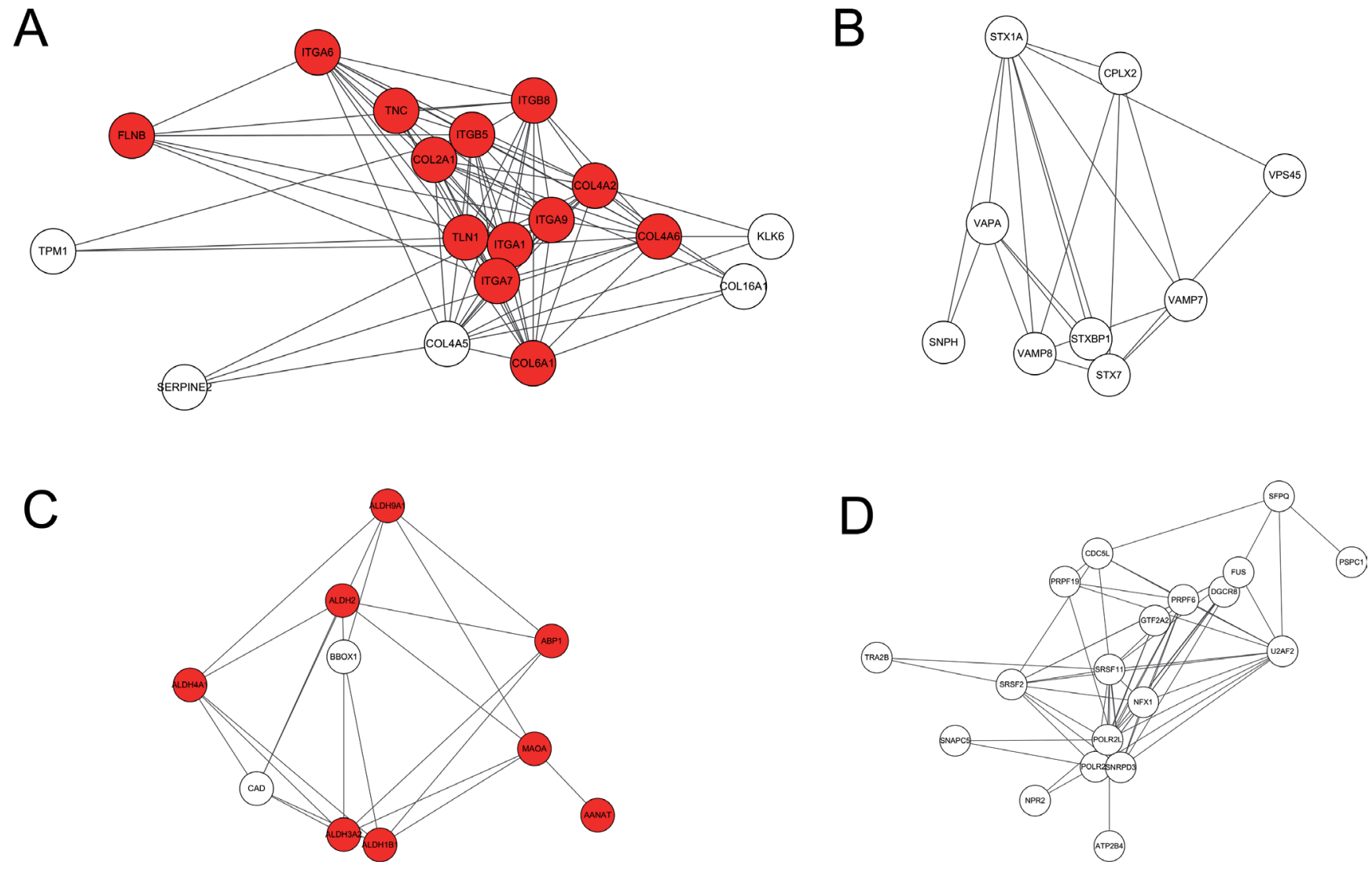

Figure 2. The interaction networks for the 4 protein complexes predicted by ClusterONE. Genes included in the KEGG pathways (analyzed using STRING) were shown in red. Cluster A-D represents protein complex 1-4 in sequence.

(hsa00903) (Table 4). Significant pathways revealed by DAVID from these protein complex 1 and 3 were consistent with those by ClusterONE. Besides, protein domain analysis and cellular component enrichment analysis further confirmed the truth of the protein complexes (Table 4).
No significant KEGG pathway (FDR $<0.05$ ) was enriched in protein complex 2. However, "SNARE interactions in vesicular transport (hsa04130)" was acquired if the criterion was broadened to p-value $<0.05$ (Table 4). SNARE is mainly involved in fusion between extracellular transport vesicle and cell

Table 4. Summary of the 4 protein complexes

\begin{tabular}{|c|c|c|c|c|c|c|}
\hline $\begin{array}{l}\text { Protein } \\
\text { complex }\end{array}$ & Protein domains & $\begin{array}{l}\text { Relevant } \\
\text { pathway }\end{array}$ & Cellular component & Gene list & Quality & $\mathrm{P}$-value \\
\hline 1 & $\begin{array}{l}\text { EGF; } \\
\text { EGF-like region; } \\
\text { extracellular }\end{array}$ & $\begin{array}{l}\text { hsa04510 } \\
\text { hsa04512 } \\
\text { hsa05412 } \\
\text { hsa05222 } \\
\text { hsa04810 }\end{array}$ & $\begin{array}{l}\text { Macromolecular } \\
\text { complex }(50 \%) \\
\text { Extracellular region } \\
(40 \%)\end{array}$ & $\begin{array}{l}\text { TPM1, TNC, TLN1, SERPINE2, KLK6, ITGB8, ITGB5, } \\
\text { ITGA9, ITGA7, ITGA6, ITGA1, FLNB, COL6A1, } \\
\text { COL4A6, COL4A5, COL4A2, COL2A1, COL16A1 }\end{array}$ & 0.536 & $2.657 \mathrm{E}-4$ \\
\hline 2 & $\begin{array}{l}\text { Sec1-like protein; Syntaxin } \\
\text { N-terminal; Synaptobrevin; }\end{array}$ & hsa04130 & Membrane (75\%) & $\begin{array}{l}\text { VPS45, VAPA, VAMP8, VAMP7, STXBP1, STX7, } \\
\text { STX1A, SNPH }\end{array}$ & 0.668 & 0.002 \\
\hline 3 & $\begin{array}{l}\text { Aldehyde dehydrogenase } \\
\text { N-terminal, conserved site }\end{array}$ & $\begin{array}{l}\text { hsa00380 } \\
\text { hsa00330 } \\
\text { hsa00903 }\end{array}$ & Organelle (100\%) & $\begin{array}{l}\text { CAD, BBOX1, ALDH9A1 } \\
\text { ALDH4A1, ALDH3A2, ALDH2, ALDH1B1, ABP1, } \\
\text { AANAT }\end{array}$ & 0.497 & 0.006 \\
\hline 4 & $\begin{array}{l}\text { RNA recognition motif RNP-1; } \\
\text { nucleotide-binding alpha-beta } \\
\text { plait }\end{array}$ & $\begin{array}{l}\text { hsa03040 } \\
\text { hsa00230 } \\
\text { hsa03020 }\end{array}$ & $\begin{array}{l}\text { Organelle }(72 \%) \\
\text { Membrane enclosed } \\
\text { lumen }(35 \%)\end{array}$ & $\begin{array}{l}\text { U2AF2, TRA2B, SRSF2, SRSF11, SNRPD3, SNAPC5, } \\
\text { SFPQ, PSPC1, PRPF6, PRPF19, POLR2L, POLR2F, } \\
\text { NPR2, NFX1, GTF2A2, FUS, DGCR8, CDC5L }\end{array}$ & 0.483 & 0.008 \\
\hline
\end{tabular}

Quality: quality of the cluster, calculated as percentage of heavy weight edge in the cluster accounting for all; p-value: the reliability of the cluster. 


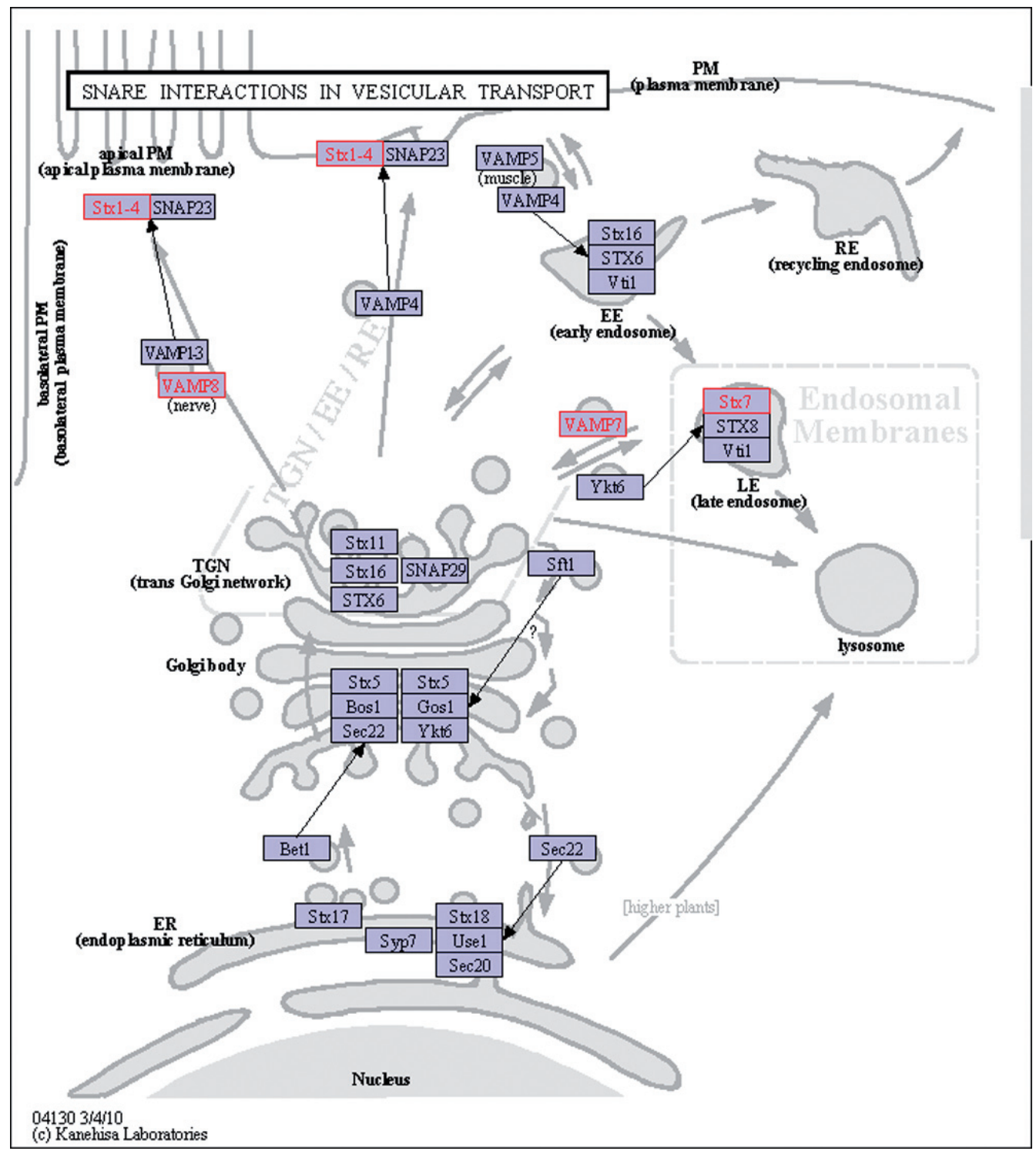

Figure 3. Schematic diagram for SNARE interactions in vesicular transport (hsa04130).

membrane or extracellular substance transport by lysosomals (Figure 3). According to GO cellular component analysis, 75\% of the proteins were located in cell membrane, confirming its roles in membrane fusion. Moreover, this kind of pathway was associated with diseases, such as pseudo hypoparathyroidism, cerebral dysgenesis and neuropathy. Therefore, this protein complex should exist in the DEGs.

In protein complex $4,75 \%$ proteins were located in organelles. Protein domain analysis and KEGG pathways were related to RNA recognition, post-transcriptional splicing and purine metabolism. This complex was also validated by Interpro, $\mathrm{GO}$ cellular component analysis and KEGG pathway analysis (FDR $>0.05$, p-value $<0.05$ ). It's observed in retinitis pigmentosa (hsa03040) (Table 4). Pigmentary degradation was reported in two male patients with pituitary tumors [19]. This information suggested the certainty of protein complex 4 .

\section{Discussion}

A total of 1911 differentially expressed probes corresponding to 1712 DEGs were identified in prolactinomas compared to normal pituitary glands. PPI networks were constructed for 121 protein products of the DEGs and 19 significant KEGG pathways were revealed as well. Four protein complexes were predicted using ClusterONE and they were validated in terms of enriched pathways, protein domain, GO cellular component and literatures. Protein complex 1 was linked to focal adhesion, cytoskeleton, extracellular matrix interactions, as well 
as cardiac arrhythmias and lung cancer. Protein complex 3 was related to tryptophan, arginine and proline metabolic pathway.

As shown in Table 3, a considerable part of pathways were associated with cancers. Given prolactinoma was also a type of pituitary tumor, it's not unexpected that these pathways were enriched in the DEGs. Moreover, it granted reliability to our study. Pathways related to metabolisms of tryptophan, arginine, proline and others were also significant. Pituitary gland is an important endocrine gland secreting nine hormones that regulate homeostasis. Obviously, abnormality in this gland will cause metabolic disorder. The study by Bergstrom et al. indicate a remarkable decrease of the amino acid metabolism in prolactinomas after bromocriptine treatment [20,21], which verified the disorder in metabolisms and supported our result in certain degree. As stated earlier, Tryptophan metabolites include 5-HT. 5-HT stimulation of GABAergic neurons and indirect modulation of prolactin release by $5-\mathrm{HT}$ is considered of one of the mechanisms underlying the association of antidepressants with hyperprolactinaemia [22]. It indicated the metabolism of tryptophan might be a candidate target for prolactinoma treatment.

Besides, MAPK signaling pathway and ECM-receptor interaction were also enriched in the DEGs. Mitogen-activated protein kinase (MAPK) signal transduction pathway is involved in regulation of prolactin gene expression by estrogen [23]. Pei et al. report that MAPK cascade regulates pituitary tumor-transforming gene function, an oncogene acting as a transcriptional activator [24].

To further describe the interactions between DEGs and their roles in the development of prolactinoma, protein complexes were predicted by ClusterONE and four complexes were revealed. Many integrins that mediates cell-cell and cell-extracellular matrix interactions were included in protein complex 1, and that was in accordance with enriched signal transduction pathways. Collagens were extracellular matrix proteins and they were also included in protein complex 1. Our results supported the idea that differential expression of extracellular matrix components, integrins and matrix metalloproteinase contributes to the control of pituitary hormone production and cell proliferation during tumorigenesis [25]. Similarly, the role of ECM receptor interactions pathway is revealed in the tumorigenesis and progression of Growthhormone-secreting pituitary adenomas [26]. Protein complex 3 was associated with amino acid metabolism, tryptophan, arginine and proline metabolisms, as well as decomposition of limonene and pinene, and that was also in line with enriched signaling pathways. It might explain increased secretion of PRL and other hormones. A number of aldehyde dehydrogenases (ALDH) genes were enriched in protein complex 3 as well. ALDH are a group of enzymes catalyzing the oxidation of acetaldehyde and transforming it into acetate [27]. Abnormal activity of ALDH is implicated in a variety of cancers such as lung, colorectal and breast cancer [28-30].This study indicated ALDH is involved in prolactinoma as well, and might be a possible biomarker for this disease. Besides, SNARE interactions in vesicular transport was "partially" enriched in protein complex 2, which was also associated with hormone secretion [31]. Garcia et al. propose a SNARE-targeted strategy to inhibit secretion of growth hormone [32]. It might be useful for treatment of prolactinoma. Garcia et al. find that vesicle-associated membrane protein $2 \& 3$ (VAMP2\&3), SNAP-23 and syntaxin 1 are the predominant SNARE-proteins in somatotroph adenomas. Therefore, VAMP-associated protein A (VAPA), VAMP7 and VAMP8 were worthy of further investigations to verify their expression profiles in prolactinoma. Protein complex 4 was linked to RNA recognition and splicing, which contributed to the disorder during development of prolactinoma.

When summarizing, our study supported previous findings and provided new insights into the molecular mechanisms, especially hormone secretion-related genes like VAPA, VAMP7\&8. This knowledge also provided possible candidate targets such as metabolism of tryptophan and ALDH activity. That would benefit future therapy development for prolactinoma.

\section{References}

[1] MELMED S, CASANUEVA FF, HOFFMAN AR, KLEINBERG DL, MONTORI VM et al. Diagnosis and treatment of hyperprolactinemia: an Endocrine Society clinical practice guideline. Clinical Endocrinology and Metabolism 2011; 96 : 273-288. http://dx.doi.org/10.1210/jc.2010-1692

[2] GILLAM MP, MOLITCH ME, LOMBARDI G, COLAO A. Advances in the treatment of prolactinomas. Endocrine reviews 2006; 27: 485-534. http://dx.doi.org/10.1210/er.2005-9998

[3] $\mathrm{OH}$ MC, AGHI MK. Dopamine agonist-resistant prolactinomas: A review. Journal of neurosurgery 2011; 114: 1369-1379.

[4] SANTOS-SILVA CM, BARBOSA FR, LIMA GA, WARSZAWSKI L, FONTES R et al. BMI and metabolic profile in patients with prolactinoma before and after treatment with dopamine agonists. Obesity 2011; 19: 800-805. http://dx.doi. org/10.1038/oby.2010.150

[5] LV H, LI C, GUI S, ZHANG Y. Expression of estrogen receptor $\alpha$ and growth factors in human prolactinoma and its correlation with clinical features and gender. Journal of endocrinological investigation 2012; 35: 174-180.

[6] COOPER O, MAMELAK A, BANNYKH S, CARMICHAEL J, BONERT V et al. Prolactinoma ErbB receptor expression and targeted therapy for aggressive tumors. Endocrine 20131-10. 2012-0051 [pii].

[7] TONG Y, ZHOU J, MIZUTANI J, FUKUOKA H, REN S-G et al. CEBPD suppresses prolactin expression and prolactinoma cell proliferation. Molecular endocrinology 2011; 25: 1880-1891. http://dx.doi.org/10.1210/me.2011-1075

[8] PALMIERI D, VALENTINO T, DE MARTINO I, ESPOSITO F, CAPPABIANCA P et al. PIT1 upregulation by HMGA proteins has a role in pituitary tumorigenesis. Endocrinerelated cancer 2012; 19: 123-135. http://dx.doi.org/10.1530/ ERC-11-0135 
[9] YASUNO H, WATANABE T, MIYAMOTO Y, KANDORI $\mathrm{H}$, YAMASAKI $\mathrm{H}$ et al. Expression of steroidogenic factor 1 and pituitary specific transcription factor 1 in rat pituitary adenomas. J Toxicol Pathol 2013; 26: 209-213.doi: 10.1293/ tox.26.209 http://dx.doi.org/10.1293/tox.26.209

[10] TONG Y, ZHENG Y, ZHOU J, OYESIKU NM, KOEFFLER $\mathrm{HP}$ et al. Genomic characterization of human and rat prolactinomas. Endocrinology 2012; 153: 3679-3691.doi: 10.1210/ en.2012-1056. http://dx.doi.org/10.1210/en.2012-1056

[11] DAVIS S, MELTZER PS. GEOquery: a bridge between the Gene Expression Omnibus (GEO) and BioConductor. Bioinformatics 2007; 23: 1846-1847.doi: 10.1093/bioinformatics/ btm254. http://dx.doi.org/10.1093/bioinformatics/btm254

[12] SMYTH GK. Linear models and empirical bayes methods for assessing differential expression in microarray experiments. Statistical applications in genetics and molecular biology 2004; 3: Article3.doi: 10.2202/1544-6115.1027. http://dx.doi. org/10.2202/1544-6115.1027

[13] DENNIS G, JR., SHERMAN BT, HOSACK DA, YANG J, GAO W et al. DAVID: Database for Annotation, Visualization, and Integrated Discovery. Genome biology 2003; 4: P3. http:// dx.doi.org/10.1186/gb-2003-4-5-p3

[14] FRANCESCHINI A, SZKLARCZYK D, FRANKILD S, KUHN M, SIMONOVIC $M$ et al. STRING v9.1: proteinprotein interaction networks, with increased coverage and integration. Nucleic acids research 2013; 41: D808-815. doi: 10.1093/nar/gks1094. http://dx.doi.org/10.1093/nar/ gks1094

[15] NEPUSZ T, YU H, PACCANARO A. Detecting overlapping protein complexes in protein-protein interaction networks. Nature methods 2012; 9: 471-472.doi: 10.1038/nmeth.1938. http://dx.doi.org/10.1038/nmeth.1938

[16] LIN H, SHIH S, YAO M, HUANG T. Relapse of acute myeloid leukemia at the pituitary gland: a case report and review ofliterature. Endocr Pathol 2012; 23: 172-176. http://dx.doi. org/10.1007/s12022-012-9203-1

[17] SANADA H, MIYAZAKI M. Regulation of tryptophan-niacin metabolism by hormones. Journal of nutritional science and vitaminology 1979; 26: 617-627. http://dx.doi.org/10.3177/ jnsv. 26.617

[18] TU H, RADY PL, JUELICH T, SMITH EM, TYRING SK et al. Cytokine Regulation of Tryptophan Metabolism in the Hypothalamic-Pituitary-Adrenal (HPA) Axis: Implications for Protective and Toxic Consequences in Neuroendocrine Regulation. Cell Mol Neurobiol 2005; 25: 673-680. http:// dx.doi.org/10.1007/s10571-005-4007-1

[19] COSEMANS I, DEMAEREL P, WETS B, HAUWERE BD, SPILEERS W. Retinitis pigmentosa in association with acromegaly: a case report. Doc Ophthalmol 1999; 98: 175-181. http://dx.doi.org/10.1023/A:1002473728642

[20] BERGSTROM M, MUHR C, LUNDBERG PO, BERGSTROM $\mathrm{K}, \mathrm{GEE} \mathrm{AD}$ et al. Rapid decrease in amino acid metabolism in prolactin-secreting pituitary adenomas after bromocriptine treatment: a PET study. J Comput Assist Tomogr 1987; 11: 815-819. http://dx.doi.org/10.1097/00004728-198709000$\underline{00014}$
[21] BERGSTROM M, MUHR C, LUNDBERG PO, BERGSTROM K, LUNDQVIST $\mathrm{H}$ et al. Amino acid metabolism in pituitary adenomas. Acta Radiol Suppl 1986; 369: 412-414. M002451200 [pii].

[22] COKER F, TAYLOR D. Antidepressant-induced hyperprolactinaemia. CNS drugs 2010; 24: 563-574. http://dx.doi. org/10.2165/11533140-000000000-00000

[23] WATTERS JJ, CHUN T-Y, KIM Y-N, BERTICS PJ, GORSKI J. Estrogen modulation of prolactin gene expression requires an intact mitogen-activated protein kinase signal transduction pathway in cultured rat pituitary cells. Molecular endocrinology 2000; 14: 1872-1881. http://dx.doi.org/10.1210/ mend.14.11.0551

[24] PEI L. Activation of mitogen-activated protein kinase cascade regulates pituitary tumor-transforming gene transactivation function. J Biol Chem 2000; 275: 31191-31198.doi: 10.1074/ jbc.M002451200 http://dx.doi.org/10.1074/jbc.M002451200

[25] PAEZ-PEREDA M, KUCHENBAUER F, ARZT E, STALLA G. Regulation of pituitary hormones and cell proliferation by components of the extracellular matrix. Brazilian journal of medical and biological research 2005; 38: 1487-1494. http:// dx.doi.org/10.1590/S0100-879X2005001000005

[26] JIANG Z, GUI S, ZHANG Y. Analysis of differential gene expression by bead-based fiber-optic array in growthhormone-secreting pituitary adenomas. Experimental and therapeutic medicine 2010; 1: 905-910.

[27] KLYOSOV AA. Kinetics and specificity of human liver aldehyde dehydrogenases toward aliphatic, aromatic, and fused polycyclic aldehydes. Biochemistry 1996; 35: 4457-4467. http://dx.doi.org/10.1021/bi9521102

[28] JIANG F, QIU Q, KHANNA A, TODD NW, DEEPAK J et al. Aldehyde dehydrogenase 1 is a tumor stem cell-associated marker in lung cancer. Molecular Cancer Research 2009; 7: 330-338. http://dx.doi.org/10.1158/1541-7786.MCR-08$\underline{0393}$

[29] CHARAFE-JAUFFRET E, GINESTIER C, IOVINO F, TARPIN $\mathrm{C}$, DIEBEL $\mathrm{M}$ et al. Aldehyde dehydrogenase 1-Positive cancer stem cells mediate metastasis and poor clinical outcome in inflammatory breast cancer. Clinical Cancer Research 2010; 16: 45-55. http://dx.doi.org/10.1158/1078-0432.CCR-09-1630

[30] JELSKI W, ZALEWSKI B, SZMITKOWSKI M. Alcohol dehydrogenase $(\mathrm{ADH})$ isoenzymes and aldehyde dehydrogenase (ALDH) activity in the sera of patients with liver cancer. Journal of clinical laboratory analysis 2008; 22: 204-209. http:// dx.doi.org/10.1002/jcla.20241

[31] STENOVEC M, GON ALVES PP, ZOREC R. Peptide Hormone Release Monitored From Single Vesicles in „Membrane Lawns" of Differentiated Male Pituitary Cells: SNAREs and Fusion Pore Widening. Endocrinology 2013; 154: 1235-1246. http://dx.doi.org/10.1210/en.2012-2022

[32] GARCIA EA, TRIVELLIN G, AFLOREI ED, POWELL M, GRIEVE J et al. Characterization of SNARE Proteins in $\mathrm{Hu}-$ man Pituitary Adenomas: Targeted Secretion Inhibitors as a New Strategy for the Treatment of Acromegaly? The Journal of Clinical Endocrinology \& Metabolism 2013; 98: E1918-E1926. http://dx.doi.org/10.1210/jc.2013-2602 